\title{
Sex Differences and Thyroid Hormone Sensitivity of Hippocampal Pyramidal Cells
}

\author{
Elizabeth Gould, Anita Westlind-Danielsson, Maya Frankfurt, and Bruce S. McEwen \\ Laboratory of Neuroendocrinology, Rockefeller University, New York, New York 10021
}

In an effort to determine if sex differences exist in the morphologic characteristics of pyramidal cells and granule cells of the hippocampal formation and whether sex plays a role in determining thyroid hormone sensitivity of these neuronal populations, we used single-section Golgi impregnation to examine the effects of neonatal thyroid hormone administration on hippocampal cells from the brains of adult rats of both sexes. Quantitative analyses of control brains revealed sex differences in the number of primary dendrites and the number of spines on the apical dendritic shaft of CA3 pyramidal cells. These differences showed opposite trends; females possessed more primary dendrites, whereas males showed more apical excrescences. Neonatal treatment with thyroid hormone resulted in long-lasting and dramatic changes of the entire CA3 pyramidal cell. CA3 pyramidal cells from thyroid hormone-treated animals showed significantly larger cell body areas, greater numbers of dendritic branchpoints, and longer dendrites. In addition, CA3 pyramidal cells from thyroid hormone-treated animals showed changes in the morphological characteristics which were shown to be sexually dimorphic; treatment resulted in significantly greater numbers of both primary dendrites and apical excrescences. These treatment differences occurred in both sexes and were of equal magnitude, regardless of sex.

On the other hand, no sex differences in the morphologic parameters examined were detected for pyramidal cells in the CA1 region. Moreover, neonatal thyroid hormone treatment did not affect the cell body area, dendritic branch points, or the length of dendrites of these cells. However, neonatal thyroid hormone treatment resulted in a significant increase in dendritic spine density of both the apical and basal dendritic trees. No significant sex differences or thyroid hormone effects were observed for granule cells of the dentate gyrus.

These observations suggest that developing hippocampal pyramidal cells of the CA3 region are dramatically affected by excess thyroid hormone and that the resultant effects are persistent well into adulthood. Furthermore, sex differences exist in this neuronal population, but both sexes respond in an equal manner to thyroid hormone. Within the hippocampal

Received Mar. 21, 1989; revised Aug. 28, 1989; accepted Oct. 4, 1989

This work was supported by MH 41256 (B.S.M.), MH15125 (E.G.), The Lounsbery Foundation, and The MacArthur Foundation. A.W.-D. was supported by a grant from the Swedish Natural Science Research Council.

Correspondence should be addressed to Elizabeth Gould, 290, 1230 York Avenue, New York, NY 10021.

Copyright (C) 1990 Society for Neuroscience $0270-6474 / 90 / 030996-08 \$ 02.00 / 0$ formation, these effects appear to be somewhat specific to CA3 pyramidal cells as no sex differences were observed in CA1 pyramidal cells and granule cells.

The hippocampus has received considerable attention due to its proposed role in a number of important behavioral functions, such as emotional responses (Papez, 1937; Green, 1964) and memory (Olton, 1983; Squire, 1983), as well as its involvement in a variety of pathological conditions, including Alzheimer's disease (Hyman et al., 1984) and epilepsy (Green, 1960). An understanding of the factors which influence the development and maintenance of the principal efferent source of the hippocampus, the pyramidal cclls, is necessary in order to elucidate the neuroanatomical substrates of these processes and diseases. The hippocampus appears to be particularly sensitive to thyroid hormone as developmental thyroid dysfunction yields a variety of morphologic aberrations (Rabie et al., 1979; Lauder and Mugnaini, 1980; Rami et al., 1986a, b). The presence of thyroid hormone receptors in this neural region strongly reinforces this contention (Dratman et al., 1982). In addition, previous studies support the notion that the hippocampus is sensitive to reproductive hormones because biochemical measures are altered with administration of sex steroids (Luine, 1985; Harrelson and McEwen, 1987) and neurochemical and morphological sex differences exist in this structure (Wimer and Wimer, 1985; Loy and Sheldon, 1987; Wimer et al., 1988). Some evidence suggests that thyroid hormones and reproductive hormones are functionally linked insofar as thyroid hormone stimulates the onset of puberty (Bakke et al., 1970; Cramer and Ford, 1977). Furthermore, a few studies indicate that a sex difference may exist in sensitivity of the brain to thyroid hormones (Ford and Rhines, 1970; Bleecker et al., 1971).

The majority of studies regarding the influence of hormones on the hippocampus during development and adulthood have focused largely on intrinsic neurons (Lauder and Mugnaini, 1980; Wimer and Wimer, 1985; Rami et al., 1986a; Wimer et al., 1988) or regions of the hippocampus without reference to specific cell types (Luine, 1985; Harrelson and McEwen, 1987; Loy and Sheldon, 1987). In comparison, the number of studies which have focused on thyroid hormone effects on pyramidal cells are scarce (Rami et al., 1986b), and the possibility that sex differences are affected by thyroid hormone has not yet been examined. In order to determine if sex differences exist in hippocampal neurons and if sex plays a role in determining thyroid hormone sensitivity, we examined the effects of neonatal thyroid hormone treatment on morphologic characteristics of Golgi-impregnated hippocampal pyramidal cells of both the $\mathrm{CA} 1$ and $\mathrm{CA} 3$ regions, from the brains of adult rats of both sexes. In addition, intrin- 
sically projecting granule cells of the dentate gyrus were examincd.

\section{Materials and Methods}

Thyroid hormone treatment. Newborn Sprague-Dawley rat pups from 6 litters were used for this study. On the day after birth (P1), the rat pups were pooled and weighed, their sex determined, and an equal number (4-5) of male and female pups were distributed to each dam. At this time, all pups were subcutaneously injected with either $0.5 \mu \mathrm{g} /$ g body weight $3,3^{\prime}, 5$-triiodothyronine (T3) or the vehicle (25 $\mu$ l sesame oil) alone. Pups received similar treatments on P2 and P4. This treatment regimen was utilized because it was sufficient to induce hyperthyroid behavioral characteristics (see below) and resulted in no premature death of the experimental animals. During the treatments, pups were placed in a metal container in $35.5^{\circ} \mathrm{C}$ waterbath for approximately 10 min to avoid hypothermia. All pups were weaned at P23; the males and females were separated and housed in groups of three.

Single-section Golgi impregnation. At 2 months of age, these rats were anesthetized and transcardially perfused with $4.0 \%$ paraformaldehyde in $0.1 \mathrm{~m}$ phosphate buffer with $15 \%$ picric acid. Brains were postfixed in a solution with the same composition as the above-described perfusate for $24 \mathrm{hr}$ until processing for single-section Golgi impregnation using a modified version of the protocol previously outlined by Gabbott and Somogyi (1984). Brain sections $100 \mu \mathrm{m}$ thick were cut on a vibratome in a bath of $3.0 \%$ potassium dichromate in distilled deionized water and subsequently incubated in this solution for $24 \mathrm{hr}$. Following this, sections were briefly washed in distilled deionized water and mounted onto uncoated glass slides. Coverslips were glued over the tissue section at each corner and the slide assemblies were incubated in a solution of $1.5 \%$ silver nitrate in distilled deionized water in the dark for $24 \mathrm{hr}$. Following this, the slide assemblies were dismantled, the tissue sections removed and then rinsed briefly in distilled deionized water, dehydrated in $95 \%$ followed by absolute ethanol, cleared with Americlear, mounted onto gelatinized slides, and coverslipped under Permount.

Data analysis. All slides were coded prior to quantitative analysis, and the code was not broken until the analysis was complete. In order to insure that we were selecting cells for analysis from the same population of neurons in all brains, we confined our analysis to specific regions within the dorsal hippocampus (Fig. 1). Pyramidal cells from the CA1 region were limited to the CAla subregion, whereas thosc of the $\mathrm{CA} 3$ region were selected from CA3a,b subregions (Fig. 1). A recent study has shown that pyramidal cells of the $\mathrm{CA} 3$ region can be divided into 2 major groups in the basis of morphologic characteristics; those with short apical shafts and those with long apical shafts (Fitch et al., 1989). In order to minimize morphologic heterogeneity of CA3 pyramidal cells and to insure that the same cell populations were examined between sexes and treatment groups, $50 \%$ of the selected neurons were of the short shaft type, and the remaining $50 \%$ were of the long shaft type for each brain. In addition, granule cells of the dentate gyrus were selected only from the dorsal blade of this structure. No granule cells located at the genu region of the dentate gyrus, where the dorsal and ventral blades meet, were selected for analysis as these neurons were morphologically distinct from other granule cells. In general, Golgiimpregnated hippocampal neurons were selected for analysis if thcy possessed the following characteristics: (1) location within the designated segments of the dentate gyrus or the CAl or CA3 regions (see Fig. 1), (2) dark and consistent Golgi-impregnation throughout all dendrites, (3) a cell body in the middle third of the tissue section in order to avoid analysis of neurons extending predominantly into adjacent sections, and (4) no impregnation of adjacent neurons to impede the analysis of individual cells. Selected neurons were drawn by use of a camera lucida drawing tube $(500 \times)$ and quantitative analyses were performed on these drawings with an image-analysis morphometry program (Southern Micro Instruments). Each neuron was examined for the cross-sectional area of the cell body, the number of primary dendrites, the number of branch points of dendritic trees, and the length of the longest dendrite of dendritic trees. The total length of all dendritic segments in the plane of section was also determined for pyramidal cells of the CA 3 region. In addition, at least 2 measurements of spine density were obtained from specific regions of the dendritic tree for each cell. For each pyramidal cell, spine density was determined from the mosi lateral tertiary dendrite on the apical tree and the most lateral secondary dendrite on the basal tree. An additional dendritic spine density measurement was obtained for $\mathrm{CA} 3$ pyramidal cells. In this case, the thorny

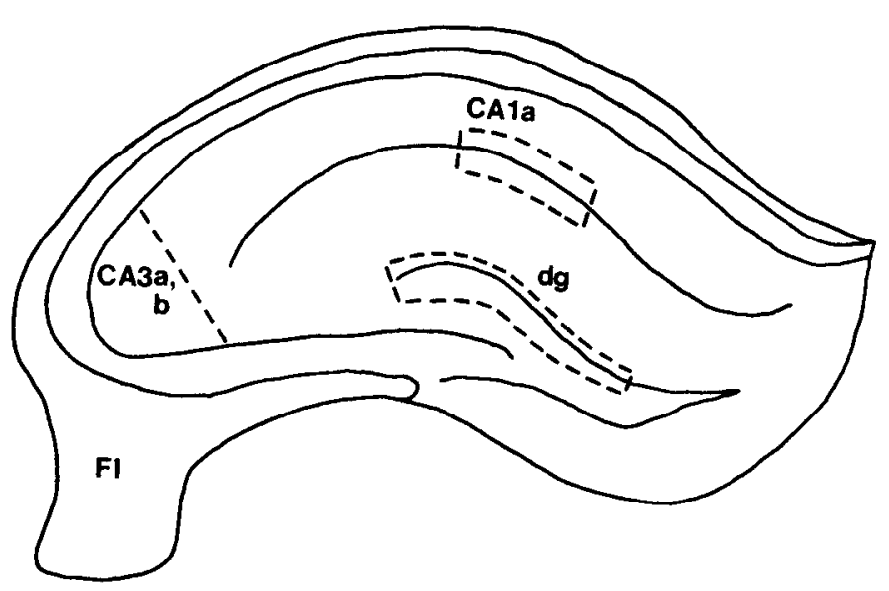

Figure 1. Camera lucida drawing of a representative section through the hippocampal formation showing the regions from which neurons were selected for analysis. Pyramidal cells or granule cells with cell bodies lying within the regions enclosed by dotted lines were selected for analysis. $d g$, dentate gyrus; $F I$, fimbria. Scale bar, $500 \mu \mathrm{m}$.

excrescences, specialized dendritic spines located on the apical shaft (Lorente de No, 1934), were counted. For each granule cell, spine density values were obtained from segments of secondary dendrites which were proximal to the soma and those which were distal to the soma. This latter measurement was always obtained from the longest dendrite. Camera lucida tracings $(1250 \times)$ were drawn of selected dendritic segments which remained within the plane of focus. All spines of the selected dendritic segment were counted, the length of the segment was determined with the image-analysis morphometry program, and spine density values were expressed as number of spines $/ 10 \mu \mathrm{m}$ dendrite. For each of the 3 neuron types, 6-8 cells were examined per brain. In all, 264 neurons and 720 dendritic segments were analyzed. Means were determined for each animal for a given variable, and these values were compared by 2 -way analysis of variance (treatment vs sex) with Tukey HSD post hoc comparisons.

\section{Results}

\section{Effects of thyroid hormone treatment: general obscrvations}

Neonatal treatment with thyroid hormone resulted in a characteristic tremor in rat pups as early as the day after the first treatment. This tremor persisted throughout the second postnatal week and thereafter became less noticeable. Premature eye opening was also observed in the hyperthyroid rats; treated rats showed eye opening as early as P10, whereas control animals did not demonstrate open eyes until the close of the second postnatal week.

\section{Morphologic characteristics of control hippocampal pyramidal cells}

Light microscopic examination of Golgi-impregnated tissue from control brains revealed reliable and consistent staining of the CA3 pyramidal cells, CA1 pyramidal cells, and granule cells. Pyramidal cells of the CA3 region possessed large cell bodies and showed extensive apical and basal dendritic trees (Fig. 2). In all cases, hippocampal pyramidal cells as well as granule cells showed a large number of dendritic spines covering dendrites. These spines were typically short and in many instances showed a terminal swelling or enlargement. Dendritic spines which were localized to the proximal portion of the apical shaft of CA3 


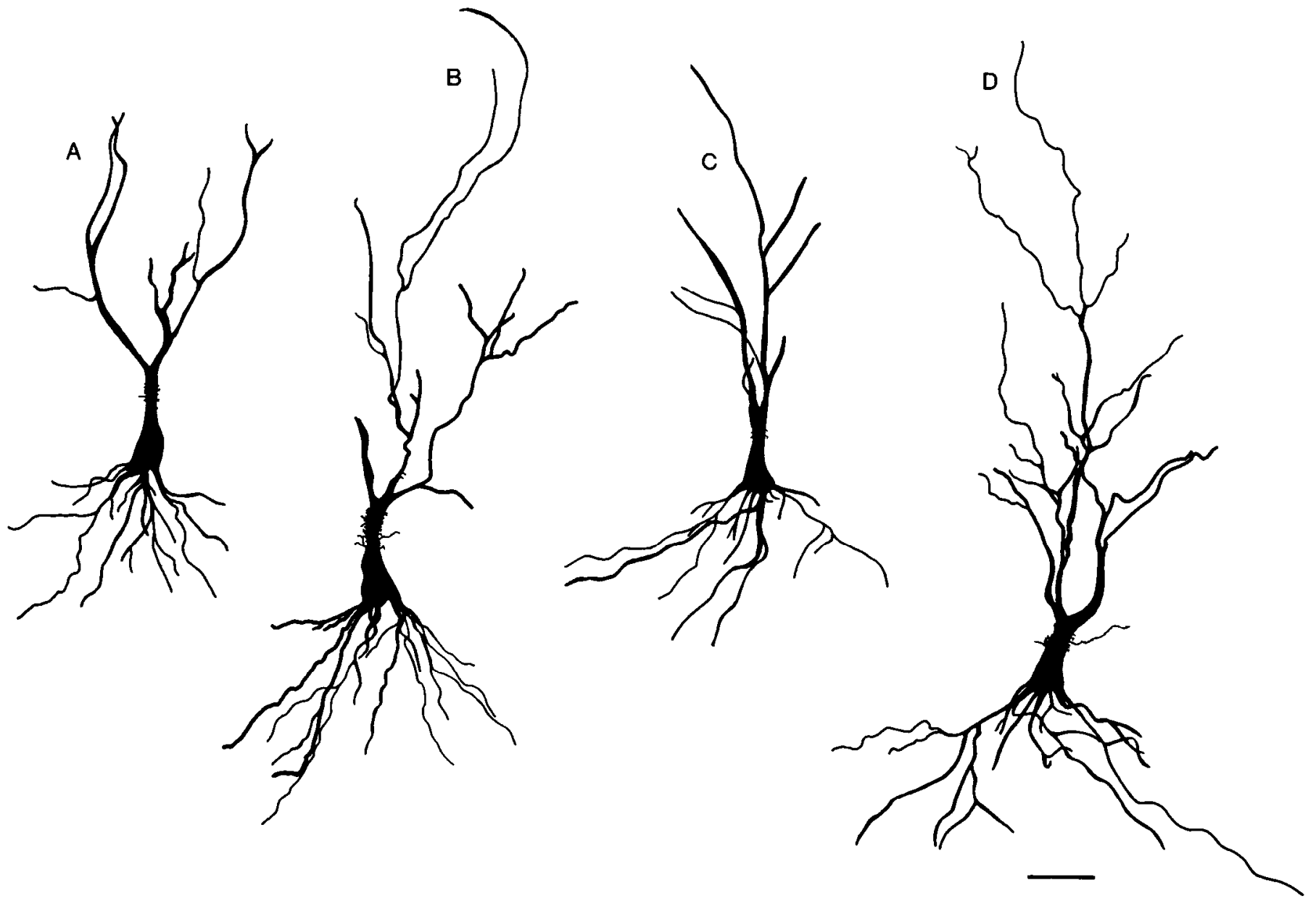

Figure 2. Camera lucida drawings of representative Golgi-impregnated CA3 pyramidal cells from male $(A, B)$ and female $(C, D)$ euthyroid $(A$, $C)$ and hyperthyroid $(B, D)$ brains. Observe the increased cell body size and more extensive dendritic trees in the neurons from thyroid hormone treated brains compared to those from control brains. Scale bar, $50 \mu \mathrm{m}$ (applies to $A-D$ ).

pyramidal cells, however, showed different characteristics. These extensions, or thorny excrescences (see Lorente de No, 1934), were often branched and showed more complex arrangements.

\section{Sex differences in hippocampal cell morphology}

No significant differences were observed for cell body area, dendritic branch points, and dendritic length between pyramidal cells from female and male control brains (see Table 1). More- over, no significant sex differences were observed for the density of dendritic spines located on both the apical and basal dendritic trees (Table 1). Significant sex differences were, however, observed in the density of apical dendritic excrescences (Figs. 24) and the number of primary dendrites (Figs. 2, 5). Surprisingly, these 2 sex differences showed opposite trends: apical dendritic excrescences were greater per unit length in the male (Fig. 4), whereas primary dendrites were greater in number in the female

\section{Table 1. Effects of neonatal thyroid hormone treatment on hippocampal CA3 pyramidal cell morphology}

\begin{tabular}{lcccc} 
Morphological variable & Control male & Hyperthyroid male & Control female & $\begin{array}{l}\text { Hyperthyroid } \\
\text { female }\end{array}$ \\
\hline Cell body area $\left(\mu \mathrm{m}^{2}\right)$ & $209.4 \pm 12.4$ & $305.5 \pm 24.5^{a}$ & $219.5 \pm 14.5$ & $289.2 \pm 13.0^{a}$ \\
Number of apical dendritic branch points & $8.1 \pm 0.4$ & $11.7 \pm 0.6^{a}$ & $7.4 \pm 0.9$ & $13.6 \pm 2.2^{a}$ \\
Number of basal dendritic branch points & $6.5 \pm 1.5$ & $13.6 \pm 0.8^{a}$ & $7.2 \pm 0.2$ & $12.7 \pm 1.4^{a}$ \\
Length of longest apical dendrite $(\mu \mathrm{m})$ & $240.7 \pm 11.6$ & $332.3 \pm 17.0^{a}$ & $262.2 \pm 29.6$ & $351.4 \pm 15.9^{a}$ \\
Length of longest basal dendrite $(\mu \mathrm{m})$ & $127.0 \pm 3.2$ & $186.2 \pm 10.8^{a}$ & $125.3 \pm 6.7$ & $207.8 \pm 12.5^{a}$ \\
Dendritic length/100 $\mu \mathrm{m}$ section & $1274.5 \pm 150.3$ & $2059.2 \pm 72.2^{a}$ & $1372.9 \pm 168.5$ & $2434.0 \pm 177.8^{a}$ \\
Number of apical dendritic spines $/ 10 \mu \mathrm{m}$ & $9.5 \pm 0.6$ & $9.5 \pm 0.7$ & $10.8 \pm 1.9$ & $10.5 \pm 2.0$ \\
Number of basal dendritic spines $/ 10 \mu \mathrm{m}$ & $7.9 \pm 1.5$ & $9.0 \pm 1.2$ & $8.5 \pm 0.6$ & $8.4 \pm 1.6$
\end{tabular}

Values represent means \pm SEM obtained from 3-4 animals. These data were evaluated with a 2-way ANOVA (treatment $\times$ sex) with Tukey HSD post hoc comparisons. "Differs from same-sex control by $p<0.01$. 

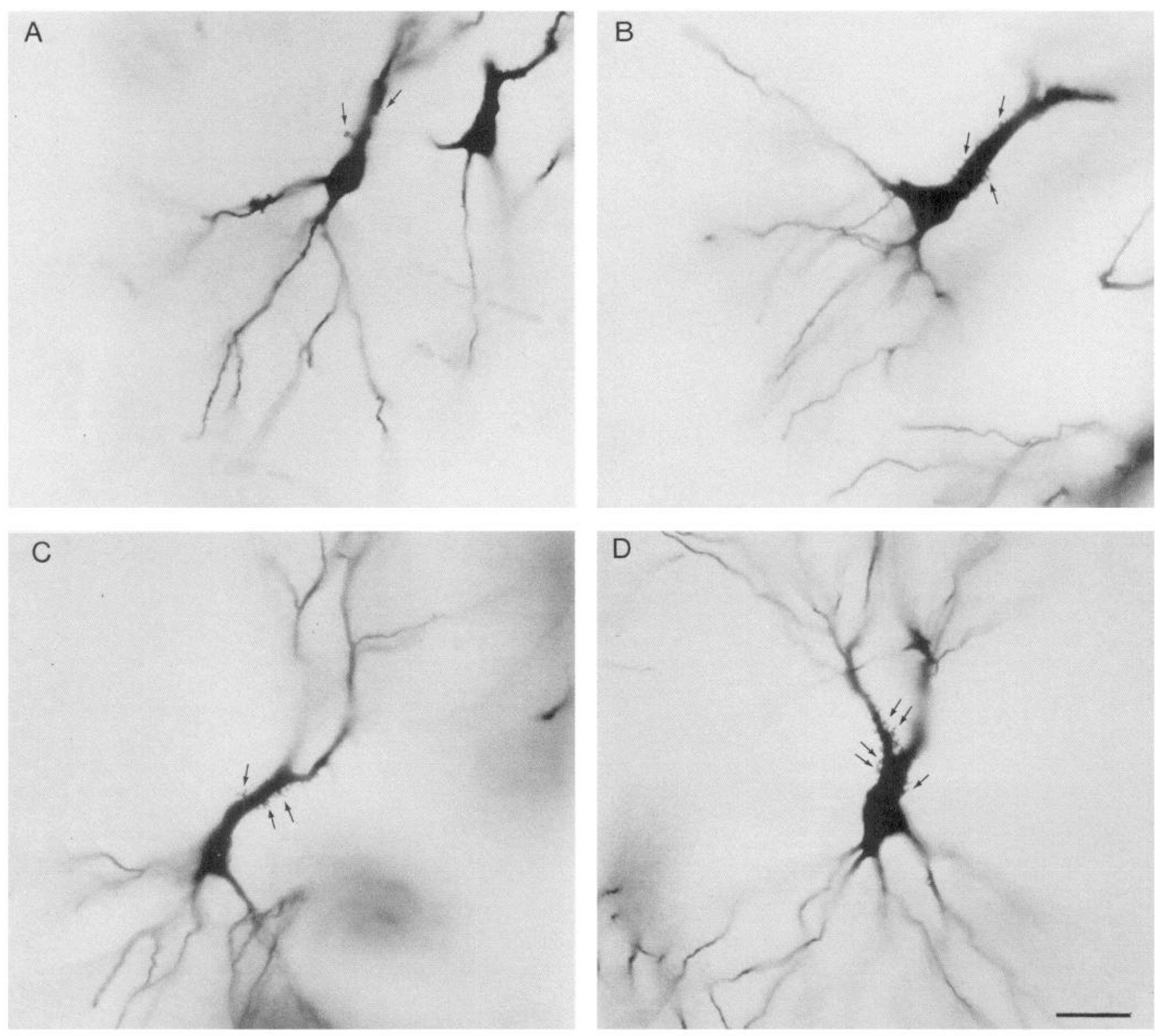

Figure 3. Photomicrographs of representative Golgi-impregnated CA 3 pyramidal cells of female $(A, B)$ and male $(C, D)$, control $(A, C)$ and thyroid hormone treated $(B, D)$ brains. Arrowheads indicate apical excrescences which are more abundant in the brains of thyroid hormone treated animals. Scale bar (in $D$ ), $50 \mu \mathrm{m}$ (applies to all frames).

\section{Table 2. Effects of neonatal thyroid hormone treatment on hippocampal CA1 pyramidal cell morphology}

\begin{tabular}{lcrrr} 
Morphological variable & Control male & Hyperthyroid male & Control female & $\begin{array}{l}\text { Hyperthyroid } \\
\text { female }\end{array}$ \\
\hline Cell body area $\left(\mu \mathrm{m}^{2}\right)$ & $199.6 \pm 6.8$ & $202.8 \pm 4.7$ & $212.9 \pm 8.4$ & $201.9 \pm 7.0$ \\
Number of apical dendritic branch points & $12.6 \pm 2.6$ & $14.1 \pm 0.8$ & $15.2 \pm 1.9$ & $16.9 \pm 2.8$ \\
Number of basal dendritic branch points & $9.5 \pm 1.7$ & $9.9 \pm 0.5$ & $7.9 \pm 1.3$ & $9.0 \pm 1.0$ \\
Length of longest apical dendrite $(\mu \mathrm{m})$ & $231.9 \pm 17.7$ & $240.5 \pm 38.0$ & $244.7 \pm 8.9$ & $234.9 \pm 10.6$ \\
Length of longest basal dendrite $(\mu \mathrm{m})$ & $138.4 \pm 14.7$ & $158.1 \pm 21.8$ & $124.1 \pm 8.9$ & $133.8 \pm 3.7$ \\
Number of primary dendrites & $4.8 \pm 0.1$ & $4.5 \pm 0.1$ & $4.2 \pm 0.1$ & $4.6 \pm 0.4$ \\
Number of apical dendritic spines $/ 10 \mu \mathrm{m}$ & $11.8 \pm 0.7$ & $17.1 \pm 1.0^{a}$ & $9.9 \pm 1.3$ & $16.5 \pm 1.8^{a}$ \\
Number of basal dendritic spines $/ 10 \mu \mathrm{m}$ & $8.4 \pm 0.7$ & $14.3 \pm 2.0^{a}$ & $9.0 \pm 2.1$
\end{tabular}

Values represent means \pm SEM obtained from 3-4 animals. These data were evaluated with a 2-way ANOVA (treatment $\times$ sex) with Tukey HSD post hoc comparisons. ${ }^{a}$ Differs from same-sex control by $p<0.05$. 


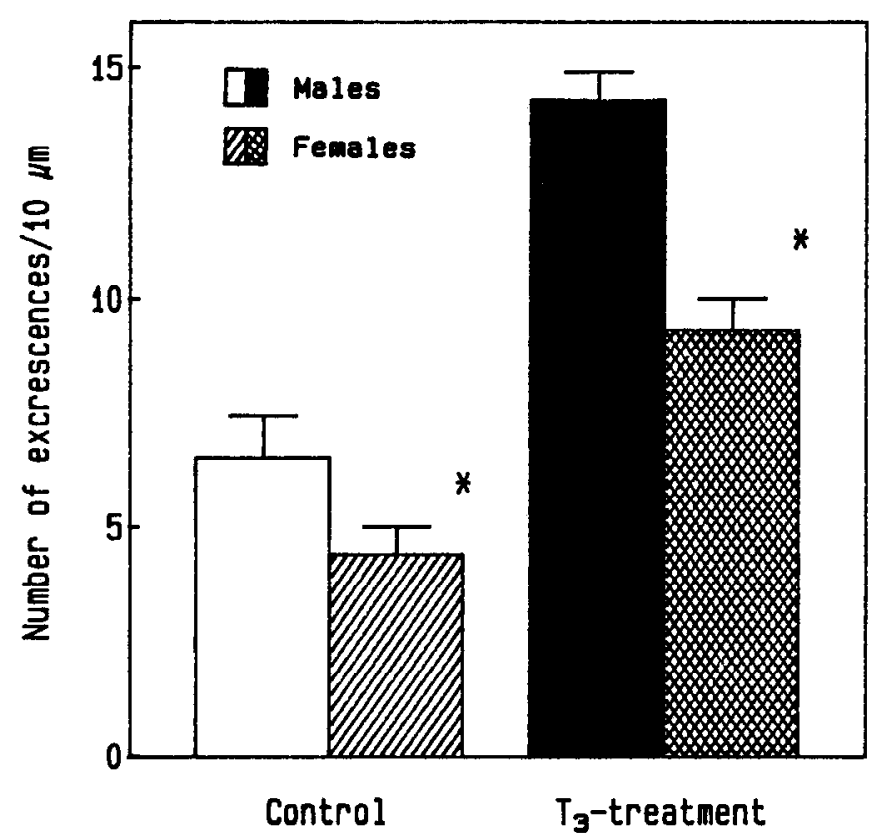

Figure 4. Number of excrescences per $10 \mu \mathrm{m}$ length of CA3 pyramidal cell apical dendrites in euthyroid and thyroid hormone treated brains of both sexes. Bars represent the mean + SEM obtained from 3-4 animals per group. Two-way ANOVA revealed no significant interaction between sex and treatment. Post hoc comparisons showed significant sex differences in both the control and treated groups. Asterisks: differs from male value of the same treatment group, $p<0.01$.

(Fig. 5). Moreover, excrescences of males were more complex in appearance, showing larger clusters with more extensive branching than those of females (Figs. 2, 3). The greater number of primary dendrites observed in female brains appeared to be the result of significantly more basal dendrites; the number of apical dendrites was consistent between sexes (Fig. 2). In addition, the basal dendritic tree of females also appeared to span a greater width (Fig. 2), possibly due to the increased number of basal dendrites.

No significant sex differences were observed in cell body area, dendritic branch points, length of the longest dendrite, or dendritic spines for pyramidal cells of the CA1 region (Table 2) and granule cells of the dentate gyrus (Table 3 ).

\section{Effects of thyroid hormone treatment on hippocampal cell morphology}

Examination of Golgi-impregnated pyramidal cells of the CA3 region from thyroid hormone-treated rats revealed morphologic characteristics which were roughly similar to control neurons (Fig. 2). Although no differences were observed in the general organization of $\mathrm{CA} 3$ hippocampal pyramidal cells, quantitative analyses of thyroid hormone-treated and control CA 3 pyramidal cells revealed striking differences in morphologic parameters between the 2 groups (Table 1). CA3 pyramidal cells from brains of hyperthyroid animals showed significantly larger cell bodies, as well as greater numbers of primary dendrites (Fig. 5). The average length of the longest dendrite, the total dendritic length within a plane of section, and the number of branch points on both the apical and basal dendritic trees were also significantly greater in the brains of animals which had been treated with thyroid hormone neonatally (Table 1, Fig. 2). Dendritic branch points appeared to be more scarce on the distal portions com-

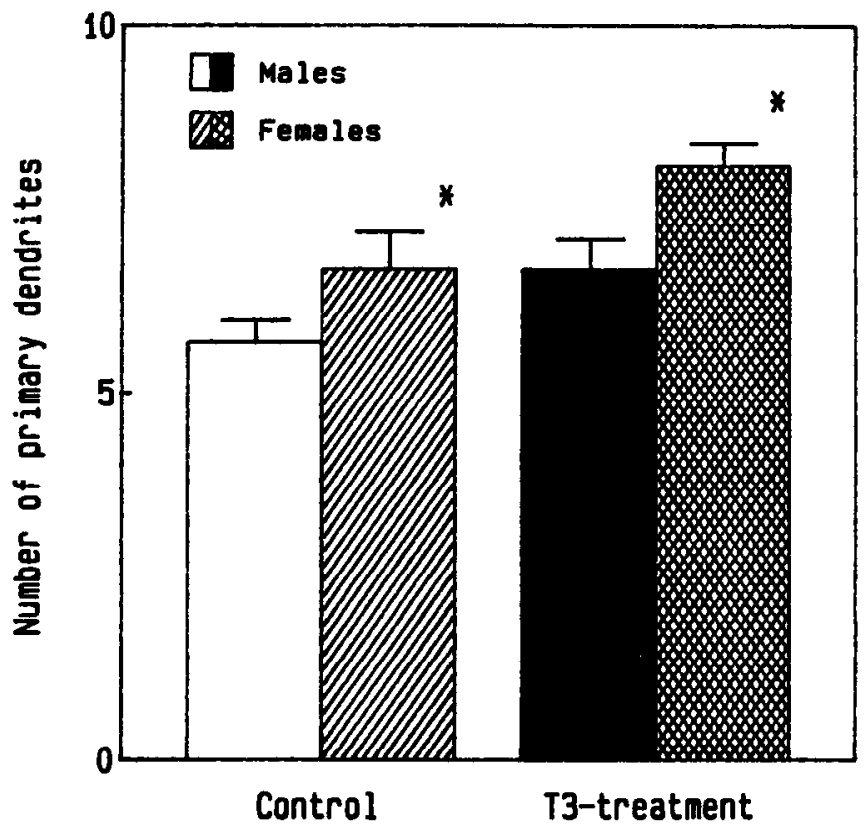

Figure 5. Number of CA3 pyramidal cell primary dendrites in control and thyroid hormone-treated brains of both sexes. Bars represent means + SEM obtained from 3-4 animals per group. Two-way ANOVA revealed no significant interaction between sex and treatment. Post hoc comparisons showed significant sex differences in both the control and treated group. Asterisks: differs from male value of the same treatment group, $p<0.01$.

pared to the proximal portions of the apical dendritic tree of CA3 pyramidal cells (Fig. 2). Following the trend observed for cell body area, dendrite number, branch points, and length, the density of excrescences was significantly greater in the thyroid hormone-treated animals compared with controls (Figs. 3, 4). In addition, these dendritic spines were more complex and showed a greater degree of branching than those observed on control pyramidal cells (Figs. 2, 3). Interestingly, neonatal thyroid treatment caused no difference in the density of spines of the apical and basal dendritic trees of CA3 pyramidal cells (Table 1).

Despite the alteration in the number of primary dendrites and excrescences with neonatal thyroid hormone treatment, the sex differences observed in controls were preserved in the treated group (Figs. 4, 5). There did not, however, appear to be an interaction between sex and thyroid hormone treatment, as both sexes showed increases in morphologic characteristics which were comparable in magnitude (Figs. 4, 5).

Quantitative analysis of CA1 pyramidal cells revealed no significant effects of neonatal thyroid hormone treatment on cell body area and number of primary dendrites (Table 2). Furthermore, the number of dendritic branch points and the length of the longest dendrite of both the apical and basal dendritic trees were unchanged by neonatal thyroid hormone treatment (Table 2). However, the density of spines located on the apical and basal dendritic trees of CAl pyramidal cells was significantly increased with thyroid hormone treatment (Table 2).

Examination of granule cells of the dentate gyrus showed no significant differences in cell body area, number of primary dendrites, number of dendritic branch points, or the length of the longest dendrite with thyroid hormone administration (Table 3). In addition, spines located on both proximal and distal gran- 
Table 3. Effect of neonatal thyroid hormone treatment on hippocampal granule cell morphology

\begin{tabular}{lcccc} 
Morphological variable & Control male & Hyperthyroid male & Control female & $\begin{array}{l}\text { Hyperthyroid } \\
\text { female }\end{array}$ \\
\hline Cell body area $\left(\mu \mathrm{m}^{2}\right)$ & $165.4 \pm 4.1$ & $155.7 \pm 0.6$ & $162.3 \pm 7.7$ & $154.3 \pm 19.1$ \\
Number of dendritic branch points & $5.4 \pm 0.2$ & $5.2 \pm 0.7$ & $5.3 \pm 0.5$ & $5.1 \pm 0.7$ \\
Length of longest dendrite $(\mu \mathrm{m})$ & $171.5 \pm 9.6$ & $169.4 \pm 14.3$ & $190.2 \pm 5.0$ & $189.6 \pm 19.3$ \\
Number of primary dendrites & $2.7 \pm 0.3$ & $2.3 \pm 0.1$ & $2.2 \pm 0.1$ & $1.8 \pm 0.2$ \\
Number of proximal spines $/ 10 \mu \mathrm{m}$ & $6.2 \pm 1.0$ & $7.1 \pm 1.4$ & $6.4 \pm 0.7$ & $6.7 \pm 1.2$ \\
Number of distal spines $/ 10 \mu \mathrm{m}$ & $8.8 \pm 0.9$ & $9.1 \pm 2.7$ & $9.4 \pm 0.5$ & $10.8 \pm 1.9$ \\
\hline
\end{tabular}

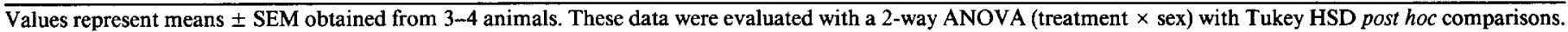

ule cell dendrites showed no significant change with neonatal thyroid hormone treatment (Table 3).

\section{Discussion}

\section{Methodologic considerations}

Although it is not possible to predict which hippocampal cells will become impregnated using the Golgi method, the selection criteria by which Golgi-impregnated neurons were chosen for analysis (see above) make it likely that the cells analyzed in this study were selected from the same populations across sexes and treatment groups.

\section{Sex differences in pyramidal cell morphology}

The observations described in this report demonstrate sex differences in morphologic characteristics of CA3 hippocampal pyramidal cells. CA3 pyramidal cells of male brains consistently showed increased numbers of excrescences on the apical dendritic shaft. In addition, these spines appeared to be more complex in appearance, with larger and more highly branched clusters, than observed in female brains. Excrescences have been identified ultrastructurally as postsynaptic clements to granulc cell mossy fibers (Raisman et al., 1965; Lauder and Mugnaini, 1980). It is possible that this difference in excrescence characteristics observed between sexes may reflect a similar sex difference in the number of mossy fibers. The recent observation that male mice have greater numbers of hippocampal granule cells than females (Wimer and Wimer, 1985; Wimer et al., 1988) suggests this may be the case.

The increased number of primary dendrites observed in CA3 hippocampal pyramidal cells of female brains appears to be due largely to an increase in basal dendrites, which probably accounts for the accompanying wider basal dendritic span. It is unclear at present what the functional significance is of such a difference. Since basal dendrites of CA3 pyramidal cells primarily receive inputs from neighboring pyramidal cells (Raisman et al., 1965; Bayer, 1985), an increase in the number of these elements might reflect increased communication within this neuronal population. Moreover, the change in the span of basal dendrites could alter the pattern of inputs necessary for summation to occur in a given pyramidal cell. It is not known, however, whether these sex differences arise from direct effects of gonadal steroids or through indirect actions on connected neuronal populations. Some evidence suggests that pyramidal cells bind estradiol (Loy et al., 1988), but further studies will be needed to determine if estradiol is directly involved in the expression of these dimorphisms. Sex differences have also been observed in the development of the cholinergic septohippocam- pal system (Loy and Sheldon, 1987). Since cholinergic synapses, arising from the medial septal nucleus, have been observed on hippocampal pyramidal cells (Frotscher and Leranth, 1985), it is also possible that sex differences in these neurons arise from primary sex differences in the cholinergic neurons of the basal forebrain (A. Westlind-Danielsson, E. Gould and B. S. McEwen, unpublished observations).

No sex differences were observed in CAl pyramidal cells and granule cells for any of the morphologic parameters examined in this study. Previous morphologic studies have demonstrated sex differences in the responsiveness of hippocampal granule cells, as well as visual cortical cells, to environmental stimuli (Juraska, 1984; Juraska et al., 1985). These reports suggest that differences between sexes may not be morphologically detectable in animals reared in noncomplex environments.

\section{Persistent effects of thyroid hormone on hippocampal morphology}

The results presented here demonstrate a profound effect of neonatal thyroid hormone treatment on the morphologic characteristics of hippocampal pyramidal cells of the CA3 region. A previous study has shown that developmental hypothyroidism causes stunted dendritic trees of hippocampal pyramidal cells at postnatal days 6 and 10 (Rami et al., 1986b). No evidence exists, however, to suggest whether this neuronal population is permanently affected by neonatal thyroid dysfunction. Our results show that a small dose of thyroid hormone, administered during a discrete neonatal period, is sufficient to cause extensive and long-lasting changes in these cells. This is particularly surprising because a variety of other neural parameters, which are influenced by thyroid hormone, appear to be only transiently affected by thryoid dysfunction. For example, pyramidal cells of the hyperthyroid cerebral cortex show a premature development of dendritic spines, but, by the close of the first postnatal month, spine density is no longer elevated in the thyroid hormone-treated brains (Salas et al., 1977). Rami and colleagues (1986b) have shown that developmental hypothyroidism results in more profound changes in dendritic morphology of CA3 than CA1 pyramidal cells at P6 and P10. The results presented in this report show that neonatal hyperthyroidism, at least using the treatment regimen of this study, affects the morphology of CA3 pyramidal cells more dramatically than CA1 pyramidal cells. It is conceivable that these differential effects occur because the 2 populations of pyramidal cells are in different stages of dendritic differentiation at the time of treatment; CA3 pyramidal cells undergo extensive dendritic restructuring during the first 2 postnatal weeks, whereas CAl pyramidal cells do not (Rami et al., 1986b). Further experimentation is needed to de- 
termine if thyroid hormone treatment administered during a time of CAl pyramidal cell dendritic differentiation would cause more profound morphologic changes in this cell population as well.

The underlying mechanisms whereby thyroid hormone stimulates dendritic growth are not yet known. Considerable evidence, however, suggests that thyroid hormone increases the synthesis of a variety of cytoskeletal elements, primarily microtubule-associated proteins, which have been linked to neurite outgrowth (Francon et al., 1977; Nunez, 1985; Hargreaves et al., 1988). Developmental hyperthyroidism and hypothyroidism have been demonstrated to accelerate and prevent, respectively, the dendritic compartmentalization of MAP1 in hippocampal pyramidal cells (Gould, 1988; N. J. Woolf, E. Gould, and L. L. Butcher, unpublished observations). These observations suggest that MAP1 may be required for the development of normal morphologic characteristics in this neuronal population.

It is conceivable that the hippocampus is permanently affected by thyroid dysfunction because it contains a population of neurons, granule cells, which undergo a final cell division during a relatively late developmental period (Bayer, 1980). Since the mossy fibers of the granule cells provide major afferents to the CA3 pyramidal cells, a change in these neurons may have profound influences on their target cells. A considerable number of studies support the notion that dendritic spines can be induced by presynaptic fibers during development (Hammori, 1973). The present study did not demonstrate a thyroid hormone effect on somata or dendritic morphology of granule cells. However, changes in the number of dentate gyrus granule cells and the number and distribution of mossy fibers in the hippocampus have been reported with developmental hypothyroidism and hyperthyroidism, respectively (Lauder and Mugnaini, 1980; Rami et al., 1986a). Thus, by directly changing its afferents, morphologic changes of excrescences could be elicited in CA3 pyramidal cells.

It is conceivable that indirect effects could account for the thyroid hormone-induced changes in dendritic spines of CAl pyramidal cells as well. Since thyroid hormone treatment did not alter the cell body area, number, length, or complexity of the CAl pyramidal cell dendrites, the increase in dendritic spine density may not reflect a generalized growth response to thyroid hormone. Instead, thyroid hormone may directly affect an afferent population of the CAl pyramidal cells. In this regard, it is interesting that CA3 pyramidal cells, which respond dramatically to neonatal thyroid hormone treatment, send a substantial projection, via Schaffer collaterals, to both the apical and basal dendritic trees (Bayer, 1985). Since cholinergic basal forebrain neurons send widespread projections to the hippocampus, the recent observation that these cells are also affected permanently by thyroid dysfunction (Gould and Butcher, 1989) is also consistent with the notion of indirect effects on pyramidal cells.

The presence of thyroid hormone-concentrating cells in the pyramidal cell layer of the adult hippocampus (Dratman et al., 1982) suggests, however, that thyroid hormone may elicit some direct effects on hippocampal pyramidal cells as well. It is likely that neonatal thyroid hormone administration directly stimulates CA3 hippocampal pyramidal cells to grow more extensive dendritic trees, while thyroid hormone-induced changes in afferent populations may indirectly cause increases in both CA3 pyramidal cell excrescences and CA1 pyramidal cell apical and basal dendritic spines.

\section{Thyroid hormone alterations of sexually dimorphic characteristics}

In addition to the effects of thyroid hormone on cell body area, dendritic branch points, and dendritic length, neonatal thyroid hormone treatment also significantly changed those morphologic characteristics which were sexually different. The change in these 2 sexually dimorphic characteristics, primary dendrites and apical excrescences, with thyroid hormone treatment was of equal magnitude, regardless of sex. This suggests that no sex difference in sensitivity to thyroid hormone exists within this neuronal population. The observations that the dendritic elements which are sexually dimorphic can be altered by thyroid hormone and that thyroid hormone influences the morphology of the entire neuron, suggest that sex hormones may play a similar but perhaps more subtle role in shaping hippocampal morphology.

As indicated above, thyroid hormone appears to be neccssary for the onset of puberty, as well for as the development of normal estrous cycling in rats (Bakke et al., 1970; Cramer and Ford, 1977). It is possible that thyroid hormone influences on the expression of secondary sex characteristics are mediated through the hippocampus since this structure is particularly sensitive to thyroid hormone (Rami et al., 1986a, b), shows a variety of sex differences, and has additionally been implicated in the onset of puberty (Willoughby and Martin, 1978). The existence of sex differences and thyroid hormone sensitivity in the principal efferent source of the hippocampus, the pyramidal cells, suggests that thyroid hormone may influence puberty onset by affecting the hippocampus. It is unclear, however, whether the sex differences observed in the present study arise before or after thyroid hormone exerts an influence over this neuronal population. Developmental studies will be necessary to determine the timing of the thyroid hormone effects as well as the appearance of sex differences.

\section{Functional considerations}

Since the major output source of the hippocampus arises from the pyramidal cells, it is likely that a change in the morphologic characteristics of this population, as observed in the present study, might result in altered electrical activity.

The hippocampus is recognized as having a relatively low threshold for seizures (Green and Shimamoto, 1953; Maclean, 1957) and a considerable number of studies have been aimed at understanding the factors and conditions which may elicit abnormal electrical activity in this structure. In this regard, it is interesting to note that a sex difference appears to exist in prevalence of epilepsy in humans (Pond et al., 1960). Furthermore, sex hormones have been demonstrated to alter the threshold for seizures (Woolley and Timiras, 1962) as well as the excitability of hippocampal pyramidal cells in rodents (Teyler et al., 1980). It is conceivable that the morphological sex differences observed in this study contribute in some way to these previously reported physiological sex differences. Although it is likely that sex hormones have a multitude of actions and a variety of targets, it is possible that sex differences in pyramidal cell morphology are related to scx-spccific responsiveness to seizure-inducing conditions and factors. Clearly, studies aimed at correlating morphological and physiological characteristics 
of the adult hippocampus will be necessary before such possibilities can be confirmed.

\section{References}

Bakke, J. L., R. J. Gellert, and N. L. Lawrence (1970) The persistent effects of perinatal hypothyroidism on pituitary, thyroidal and gonadal functions. J. Lab. Clin. Med. 76: 25-33.

Bayer, S. A. (1980) Development of the hippocampal region in the rat. I. Neurogenesis examined with $3 \mathrm{H}$ thymidine autoradiography. J. Comp. Neurol. 190: 87-114.

Bayer, S. (1985) Hippocampal region. In The Rat Nervous System, Vol. 1: Forebrain and Midhrain, G. Paxinos, ed., Academic, Sydney

Bleecker, M. L., D. H. Ford, and R. K. Rhines (1971) Accumulation of '3'I L-triiodothyronine in the rat brain: Effect of age and sex. In Influence of Hormones on the Nervous System, D. H. Ford., ed., pp. 231-239, Karger, Basel.

Cramer, E. B., and D. H. Ford (1977) Ultrastructural changes in the hypothalamo-hypophyseal axis in rats thyroidectomized at birth. In Thyroid Hormones and Brain Development, G. D. Grave, ed., Raven, New York.

Dratman, M. B., Y. Futaesaku, F. L. Crutchfield, N. Berman, B. Payne, M. Sar, and W. E. Stumpf (1982) Iodine 125-labeled triiodothyronine in rat brain: Evidence for localization in discrete neural systems. Science 215: 309-312.

Fitch, J. M., J. M. Juraska, and L. W. Washington (1989) The dendritic morphology of pyramidal neurons in the rat hippocampal CA3 area. I. Cell types. Brain Res. 479: 105-114.

Ford, D. H., and R. K. Rhines (1970) Effect of age on the accumulation of 131 I triiodothyronine in male and female rat brains and other tissues. Brain Res. 21: 265-274.

Francon, J., A. Fellous, A. M. Lennon, and J. Nunez (1977) Is thyroid a regulatory signal for microtubule assembly during brain development? Nature 266: 188-190.

Frotscher, M., and C. Leranth (1985) Cholinergic innervation of the rat hippocampus as revealed by choline acetyltransferase immunocytochemistry: A combined light and electron microscopic study. J. Comp. Neurol. 239: 237-246.

Gabbott, P. L., and J. Somogyi (1984) The "single"-section Golgiimpregnation procedure: Methodological description. J. Neurosci. Methods $11: 221-230$

Gould, E. (1988) The Effects of Thyroid Hormone on the Development of Brain Cholinergic Neurons. Doctoral dissertation, UCLA, Los Angeles, $\mathrm{CA}$.

Gould, E., and L. L. Butcher (1989) Basal forebrain neurons are sensitive to thyroid hormone. J. Neurosci. 9: 3347-3358.

Green, J. D. (1960) The hippocampus. In Handbook of Physiology, J. Field, ed., A.P.A. Washington, D.C.

Green, J. D. (1964) The hippocampus. Physiol. Rev. 44: 561-608.

Green, J. D., and T. Shimamoto (1953) Hippocampal seizures and their propagation. Arch. Neurol. Psychiatry 70:687-702.

Hammori, J. (1973) The inductive role of presynaptic axons in the development of postsynaptic spines. Brain Res. 62: 337-344.

Hargreaves, A., B. Yusta, A. Aranda, J. Avila, and A. Pascual (1988) Triiodothyronine (T3) induces neurite formation and increases synthesis of a protein related to MAP1B in cultured cells of neuronal origin. Dev. Brain Res. 38: 141-148.

Harrelson, A., and B. S. McEwen (1987) Gonadal steroid modulation of neurotransmitter-stimulated cAMP accumulation in the hippocampus of the rat. Brain Res. 404: 89-94.

Hyman, B. T., G. W. Van Hoesen, A. R. Damasio, and C. L. Barnes (1984) Alzheimer's disease: Cell-specific pathology isolates the hippocampal formation. Science 225: 1168-1170.

Juraska, J. M. (1984) Sex differences in dendritic response to differential experience in the rat visual cortex. Brain Res. 295: 27-34.
Juraska, J. M., J. M. Fitch, C. Henderson, and N. Rivers (1985) Sex differences in the dendritic branching of dentate granule cells following differential experience. Brain Res. 333: 73-80.

Lauder, J. M., and E. Mugnaini (1980) Infrapyramidal mossy fibers in the hippocampus of the hyperthyroid rat. Dev. Neurosci. 3: 248265.

Lorente de No, R. (1934) Studies on the structure of the cerebral cortex II. Continuation of the study of the ammonic system. J. Psych. Neurol. 46: 113-117.

Loy, R., and R. A. Sheldon (1987) Sexually dimorphic development of cholinergic enzymes in the rat septohippocampal system. Dev. Brain Res. 34: 156-160.

Loy, R., J. L. Gerlach, and B. S. McFwen (1988) Autoradiographic localization of estradiol-binding neurons in the rat hippocampal formation and entorhinal cortex. Dev. Brain Res. 39: 245-251.

Luine, V. N. (1985) Estradiol increases choline acetyltransferase ac tivity in specific basal forebrain nuclei and projection areas of female rats. Exp. Neurol. 89: 484-490.

Maclean, P. D. (1957) Chemical and electrical stimulation of the hippocampus in unrestrained animals. I. Methods and electroencephalographic findings. A.M.A. Arch. Neurol. Psychiatr. 78: 113-127.

Nunez, J. (1985) Microtubules and brain development: The effects of thyroid hormone. Neurochem. Int. 7: 959-968.

Olton, D. D. S. (1983) Memory functions and the hippocampus. In Neurobiology of the Hippocampus, W. Seifert, ed., pp. 335-373, Academic, London.

Papez, J. W. (1937) A proposed mechanism of emotions. Arch. Neurol. Psychiatry 38: 725-743.

Pond, D. A., B. H. Bidwell, and L. Stein (1960) A survey of epilepsy in fourteen general practices. I. demographic and medical data. Psychiatr. Neurol. Neurochir. 63: 217-229.

Rabie, A., A. J. Patel, M. C. Clavel, and J. Legrand (1979) Effect of thyroid deficiency on the growth of the hippocampus in the rat. A combined biochemical and morphological study. Dev. Neurosci. 2. 183-194.

Raisman, G., W. M. Cowan, and T. P. S. Powell (1965) The extrinsic afferent, commissural and association fibres of the hippocampus. Brain 88: 963-996.

Rami, A., A. Rabie, and A. J. Patel (1986a) Thyroid hormone and development of the rat hippocampus: Cell acquisition in the dentate gyrus. Neuroscience 19: 1207-1216.

Rami, A., A. Rabie, and A. J. Patel (1986b) Thyroid hormone and development of the rat hippocampus: Morphological alterations in granulc and pyramidal cells. Neuroscience 19: 1217-1226.

Salas, M., S. Diaz, and L. Cintra (1977) Thyroid and nutritional influences on electrocortical activity development. In Thyroid Hormones and Brain Development, G. D. Grave, ed., Raven, New York.

Squire, L. R. (1983) The hippocampus and the neuropsychology of memory. In Neurobiology of the Hippocampus, W. Seifert, ed., pp. 491-511, Academic, London.

Teyler, T. J., R. M. Vardis, D. Lewis, and A. B. Rawitch (1980) Gonadal steroids: Effects on excitability of hippocampal pyramidal cells. Science 209: 1017-1019.

Willoughby, J. O., and J. B. Martin (1978) The role of the limbic system in neuroendocrine regulation. In Limbic Mechanisms, K. F. Livingston and O. Hornykiewicz, ed., Plenum, New York.

Wimer, R. E., and C. C. Wimer (1985) Three sex dimorphisms in the granule cell layer of the hippocampus in house mice. Brain Res. 328: 105-109.

Wimer, R. E., C. C. Wimer, and L. Alameddine (1988) On the development of strain and sex differences in granule cell number in the area dentata of house mice. Dev. Brain Res. 42: 191-197.

Woolley, D. E., and P. S. Timiras (1962) The gonad-brain relationship: Effects of female sex hormones on electroshock convulsions in the rat. Endocrinology 70: 196-200. 